\title{
Narrative review of proving the causal link of recurrent laryngeal nerve injury and thyroidectomy: a medico legal appraisal
}

\author{
Patrizia Gualniera ${ }^{1}$, Serena Scurria $^{1}$, Cristina Mondello ${ }^{1}$, Alessio Asmundo ${ }^{1}$, Daniela Sapienza ${ }^{1}$, \\ Gianlorenzo Dionigi ${ }^{2}$
}

${ }^{1}$ Section of Legal Medicine, Department of Biomedical and Dental Sciences and Morphofunctional Imaging, University of Messina, Messina, Italy; ${ }^{2}$ Division for Endocrine and Minimally Invasive Surgery, Department of Human Pathology in Adulthood and Childhood "G. Barresi”, University of Messina, Messina, Italy

Contributions: (I) Conception and design: P Gualniera, D Gianlorenzo; (II) Administrative support: S Scurria, C Mondello; (III) Provision of study materials: P Gualniera, D Gianlorenzo, S Scurria; (IV) Collection and assembly of data: C Mondello, D Sapienza, S Scurria; (V) Data analysis and interpretation: P Gualniera, D Gianlorenzo, A Asmundo; (VI) Manuscript writing: All authors; (VII) Final approval of manuscript: All authors.

Correspondence to: Serena Scurria. Section of Legal Medicine, Department of Biomedical and Dental Sciences and Morphofunctional Imaging, University of Messina - A.O.U. “G. Martino” Via Consolare Valeria n. 1, 98100 Messina, Italy. Email: sscurria@unime.it.

\begin{abstract}
The recurrent laryngeal nerve (RLN) injuries are frequent complications related to thyroid surgery determining patient complaints and malpractice litigations. In the present work, the authors provide a brief review on the peculiarities of RLN injuries associated with thyroidectomy to highlight the various aspects of medicolegal assessment of causal link between surgery and nerve damage. The characteristics of thyroid disease, the anatomical peculiarities of surgery site and the nerve identification and preservation are factors that mostly influence the liability admission or rejection. In this context, the clinical records are fundamental, representing the most important probative tool. The possibility of having a set of information collected by clinical records, which allows for analysis and comparison to be made regarding the adherence to standards for thyroid surgery, is essential to set any medico-legal deliberation. However, the medicolegal evaluation can be very difficult. The practitioners involved in the medicolegal analysis of patient complaints related to this thyroidectomy complication need an in-depth knowledge of surgical technique, damage prevention activities and related clinical picture. To this must be added an adequate competence in the evaluation of the causal link (relation between the event and the injury and between that injury and the temporary/permanent impairment) based on the rigorous application of the medicolegal method.
\end{abstract}

Keywords: Recurrent laryngeal nerve (RLN); injury; thyroidectomy; near total thyroidectomy; professional liability

Submitted Feb 07, 2020. Accepted for publication Sep 10, 2020. This article was updated on December 24, 2020.

The original version was available at: http://dx.doi.org/10.21037/gs-20-203

doi: $10.21037 / g s-20-203$

\section{Introduction}

Surgery represents a medical discipline frequently involved in patient complaints if compared to other specialties as Clinics (1,2). In Italy, statistical reports from 2018 show that Orthopedics, General Surgery, Gynecology and Obstetrics are the specialties most involved in cases of alleged medical malpractice related to therapeutic errors, resulting respectively equal to $21 \%, 13.5 \%$ and $11.5 \%$ (3).

In the context of malpractice due to surgery errors, a not negligible percentage of complaints regard the thyroid surgery complications and, in particular, the recurrent laryngeal nerve (RLN) injuries during thyroidectomy, representing the $0.1-8 \%(4,5)$.

These injuries, as pointed out by other authors (6), could happen during surgical activities or in post-operative period.

During the intra-operative stage, the nerve damage is often associated with its improper identification and isolation that mostly occur when the nerve detection 
Table 1 Preoperative (A) unpredictable and (B) predicable RLN risk situations. Atypical courses of the RLN are observed in approximately a quarter of the thyroid gland operations. Preoperatively unpredictable risk situations, which can only be detected intraoperatively, are one of the main reasons for using neuromonitoring not only selectively but also routinely. Furthermore, the surgical experience pertaining to the identification, exposure, and protection of the RLN has a demonstrable influence on the nerve paresis rates (9)

\begin{tabular}{lll}
\hline No. & A. Unpredictable & B. Predicatable \\
\hline 1 & Atypical RLN pattern & Previous neck surgery \\
2 & RLN anterior to the thyroid gland & Previous radiotherapy \\
3 & RLN fixed, splayed or entrapped & Cancer \\
4 & RLN posterior to Berry ligament & Graves' disease \\
5 & Anteriorly located RLN to the Zuckerkandl's tuberculum & Lymph node metastases \\
6 & Branched RLN & Retrosternal goiter \\
7 & Antevascular RLN & Thyroiditis \\
8 & Thin RLN & \\
9 & Invaded RLN & \\
10 & Non-RLN & \\
\hline
\end{tabular}

RLN, recurrent laryngeal nerve.

appears to be difficult in relation to anomalies of common landmarks resulting from anatomic variations or alterations due to the thyroid disease or previous surgery (7). The nerve damage can be determined directly by the use of electric devices or retractors, or can be related to compression phenomena due to the inclusion in the ligation of the lower thyroid vessels (8); it may be also associated with abnormal traction activities performed to promote the dislocation and removal of bulky goiters in which adhesion phenomena between nerve and gland parenchyma can often occur [Table 1 (9)]. On the other hand, the RLN injuries may not depend on surgical activities being able to be related to endotracheal intubation; in this regard, some authors suggest several mechanism as the compression of RLN between the cuff and the overlying thyroid cartilage, when the endotracheal tube cuff is positioned in the subglottic region $(10,11)$.

During post-operative stage, the RLN injuries can occur in the early or late period. In the first case, the main cause of nerve damage is the compression mediated by haematoma due to post-surgical bleeding; thus, the nerve damage is related to hypoxic phenomena for vasa vasorum compression and occlusion. In the second case, abnormal scars and fibrotic reactions can involve the RLN with functional alteration resulting generally progressive, up to the complete cord paralysis.

The intra-operative RLN damage results in more or less clinical pictures, from neurapraxia (the temporary loss of function with full recovery after a short time) to axonotmesis and neurotmesis (associated respectively with irreversible reduction and loss of nerve function) (12).

The RLN injuries can be unilateral or bilateral. The unilateral lesion produces the loss of innervated muscles function and, consequently, the immobilization of the vocal cord mainly in paramedian or median position, determining phonation alteration which depend on both the position assumed by the vocal cord and the possibility of compensation promoted by the contralateral one (13). In such cases, the phonatory damage can be modest especially when an adequate speech therapy is implemented leading to the substantial regression of voice disorder; however, the voice affection can recur through the year for fibrotic phenomena involving the over-stressed mobile cord. The bilateral nerve damage is characterized by repercussions on voice and breathing, even serious; generally, the respiratory disorders, up to severe dyspnea, occur when the cords position is paramedian or median, while the voice disfunction (dysphonia or aphonia) prevails in intermediate position (14).

The prognostic judgment appears to be difficult because the clinical evolution is unpredictable even if it is certainly unfavorable in cases with nerve resection. The poor and unpredictable functional outcome following RLN injury has been attributed to the chaotic, misguided reinnervation of the larynx (12). Moreover, another aspect that could affect the choice of the more adequate temporal interval to 
Table 2 Inclusion and exclusion criteria for literature search (15)

\begin{tabular}{lll}
\hline No. & Inclusion criteria & Exclusion criteria \\
\hline 1 & Primary data from prospective and retrospective observational studies & Review article \\
2 & Human Studies & Studies with no relevant extractable outcomes \\
3 & Technical reports & Studies not published in English or Italian language \\
4 & Case reports & Duplicate article \\
\hline
\end{tabular}

evaluate the RLN damage effects is the therapy performed to promote the functional recovery. Anyway, some authors report that the assessment of RLN injuries outcome should be performed a long time after surgery, more than one year $(13,14)$.

For the aforementioned characteristics, the RLN injuries are a source of concern to both surgeons and patients, representing also a cause of malpractice litigations. Anecdotally, we noted that in some litigations it is not always possible to identify a direct relationship between nerve injury and the endocrine surgery. In light of this, the authors provide (I) a literature review on the RLN injuries related to thyroid surgery aiming to better define the peculiarities of medicolegal assessment; (II) we propose a rigorous standardized evaluation practice for each lesion of the recurrent laryngeal nerve that allows, among the different reference indices, to monitor the quality of surgery delivered throught the analysis of the clinical documentation. We present the following article in accordance with the NARRATIVE reporting checklist (available at http://dx.doi.org/10.21037/gs-20-203).

\section{Materials and methods}

\section{Search criteria}

This review has been conducted employing the PubMed, Medline, Cochrane Central, Scopus, Web of Science and Science Direct database. On these websites, articles between 1973 and 2016 were searched, using the key terms "recurrent laryngeal nerve", "injury", "thyroidectomy", "near total thyroidectomy", "professional liability". Specifically, the research has been restricted using variable combinations of the keywords. As inclusion criteria, the articles had to provide data on causes of RLN injuries and on prevention activities, both useful to evaluate the hypothetical assumptions for medical liability. Moreover, articles evaluating the malpractice litigation in this field were included. Thus, articles were excluded by title, abstract or full text for irrelevance to the topic in question. Multiple Authors (including Coroner and Endocrine Surgeons) review the generated a list of articles.

\section{Data abstraction}

Data were extracted from studies satisfying the inclusion and exclusion criteria and verified by all the authors [Table 2 (15)]. Any disagreements were resolved by consensus. Variables extracted included: study design, patient demographics, RLN complication rates, litigation assessemnt, follow-up.

\section{Analyses}

Our outcome of interest included RLN injury complication rates, rates of RLN monolateral and bilateral injury, verdicts on RLN injury, malpractice/litigation from RLN injury following thyroidectomy, transient and bilateral RLN injury, medicolegal assessment of RLN injury, documentation of RLN injury. According to statistics, it was not possible to conduct a meta-analysis model of these studies because the outcome of interest was not reported with a uniform standard and there was significant heterogeneity among studies in terms of design and patient characteristics. Furthermore, most of the studies in the review were case series and not comparative studies.

\section{Results}

\section{Study and information selection}

A total of 29 articles evaluating the main inclusion criteria were identified (Figure 1). The analysis of these works showed that several authors agree with the necessity of RLN identification and isolation during thyroid surgery to reduce the risk of nerve injury (16-20); in this regards it was also underlined the importance to standardize the activities of RLN identification to avoid the nerve damage during surgery $(21,22)$. On the other hand, it must be also 


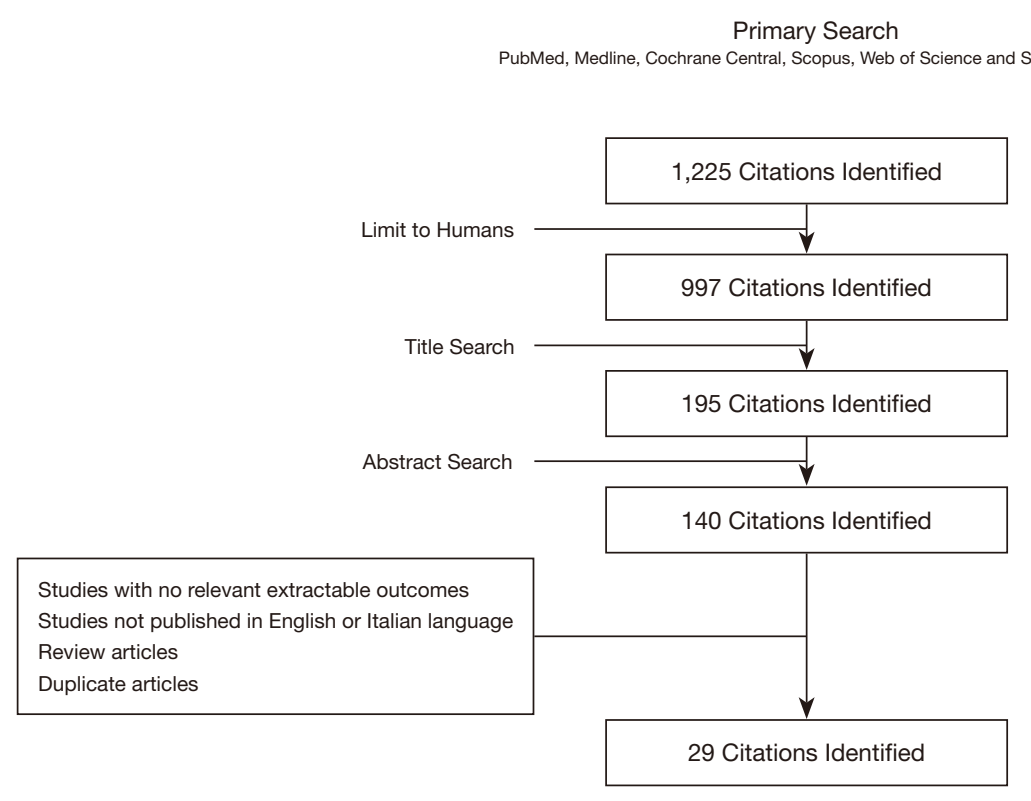

Figure 1 Attrition diagram.

highlighted that some authors reported the risk of nerve injury related to these activities, suggesting thyroidectomy without identifying RLN (23).

\section{Synthesis of individual results}

On the basis of literature review, the evidences supporting the role of routine RLN identification in injuries prevention are several $(24,25)$. This prevention appeared also improved by the implementation of intraoperative neuromonitoring techniques (26-29) even if, in complicated cases, it appeared to be useful in identification but not in eliminating the risk of nerve damage (25-30). Authors stated to carefully consider justification if neural monitoring is not used in pre-operative predictable risk procedures (26-32). One article reported that neural monitoring was subject of pleading in $57 \%$ malpractice litigations (32). In $43 \%$ of the other cases the technology was not considered because (I) non standardized usage, (II) no neural monitoring documentation included/printed in the clinical reports (32). Thus, the usefulness of neuromonitoring is not unanimously confirmed $(31,32)$.

\section{Effect of interventions}

Authors agree the importance to document pre-existing laryngeal impartment (Table 3).
Other important considerations for medico-legal evaluation of RLN injuries related to thyroidectomy regard the factors affecting negatively the adequate identification of nerve, which could be associated with increased risk of nerve injury. Some of these factors are the malignancies or the inflammatory processes complicated by nerve mounting $(23,33)$, the intraoperative hemorrhage due to both inappropriate vessels ligation or resection of very vascularized masses, the reoperation in relation to anatomical alterations or fibrotic process involving the nerve (34-37).

With particular reference to the risks related to the reoperation, several authors reported that thyroid surgery should be performed just "in a single time" $(38,39)$. Moreover, the usefulness of near-total thyroidectomy is reported to prevent the RLN injuries in high risk cases and especially when the gross extrathyroidal extension of the disease occurs (40). This surgery option involves removal of all grossly visible thyroid tissue, leaving only a small amount $(<1 \mathrm{~g})$ of tissue adjacent to the recurrent laryngeal nerve near the ligament of Berry and follows the same total thyroidectomy technique $(5,35,41,42)$; it represents a safe option only in the expert surgeons (43).

\section{Discussion}

Several factors can determine RLN injuries due to 
Table 3 The importance of documentation in thyroid surgery. Documentation is required and includes pre-existing laryngeal or RLN impairment, intraoperative and postoperative findings. Nural monitoring records nerve signal for early differentiation between RLN related and unrelated voice changes

\begin{tabular}{llll}
\hline No. & Pre-operative & Intra-operative & Post-operative \\
\hline 1 & Patient thyroid history & Surgical report & Laryngeal examination \\
& & $\bullet \quad$ Intraoperative findings & Follow-up \\
2 & Pre-operative imaging & $\bullet \quad$ Idetification of RLN & \\
3 & Patient symptoms & Pictures & \\
\hline
\end{tabular}

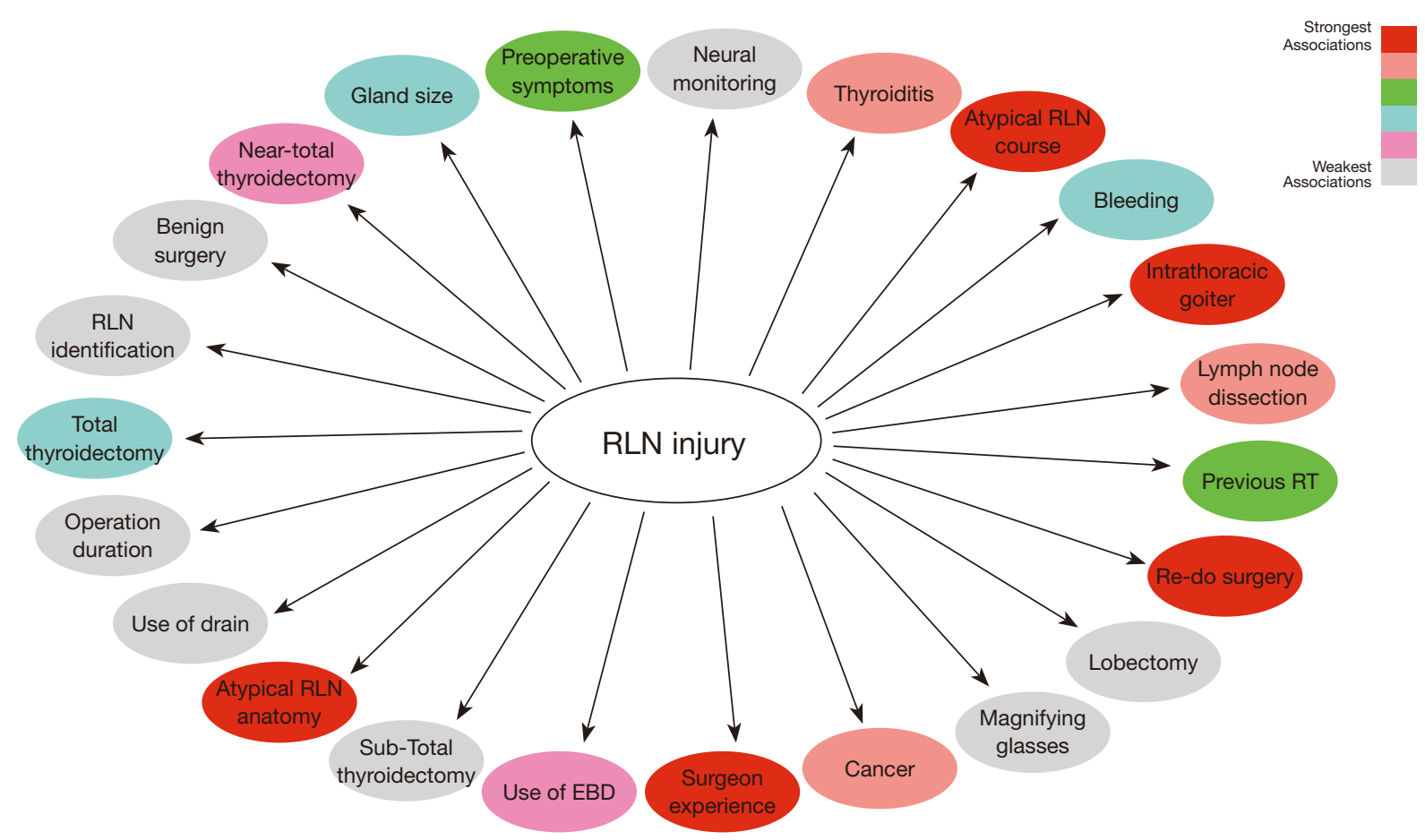

Figure 2 Relationship between RLN injury and patient, surgeon, technique and technology related variables. RLN, recurrent laryngeal nerve; EBD, energy based devices.

thyroidectomy which could be related to surgeon error determining patient complaints. The reported review summarizes the main aspects of this field to provide medicolegal considerations useful for evaluation of professional liability.

The medicolegal analysis must be aimed to the assessment of the cause of nerve damage and, thus, if it is related to surgical activities or not (the so-called causal link) (44). This is because the injury might be previously developed as complication of the thyroid disease. It is well known that malignancies, toxic goiters and thyroiditis can determine infiltration, compression or traction of nerve (45-47). Thus, the pre-operative and post-operative physical examination, reporting accurate data on breathing and voice, as well as the laryngoscopic evidences, carefully reported in clinical records, are fundamental tools for evaluation of the damage chronology (Figure 2).

The medicolegal analysis of complained professional liability could be more difficult in cases showing close connection between RLN injury and thyroidectomy. The 
Table 4 The power of laryngeal examination and neural monitoring for causal link evidence. The standards of RLN management include extensive knowledge of RLN anatomy, visual identification and functional confirmation of RLN (neural monitoring), nerve exposure, training and certainly pre- and postoperative laryngeal examination (L1 and L2, respectively). Only the association between laryngoscopy and neuromonitoring can confirm the causal link between RLN injury and surgery

\begin{tabular}{ll}
\hline No. & \multicolumn{1}{c}{ Causal link } \\
\hline 1 & L1 negative, normal vocal cord movement \\
2 & Pre-dissection/baseline vagal nerve stimulation (V1) and RLN (R1) normal ${ }^{\star, * *}$ \\
2 & Loss of EMG signal or reduced EMG signal ( $<100 \mathrm{mcV})$ during thyroid surgery^ \\
3 & Intraoperative suspect of RLN palsy \\
4 & Loss of EMG signal or reduced EMG signal end surgery (V2 and R2)^ \\
5 & L2 positive for RLN palsy/paralysis, vocal cord impairment \\
\hline
\end{tabular}

EMG, electromyography; RLN, recurrent laryngeal nerve; L1, preoperative laryngeal examination; L2, postoperative laryngeal examination; V1, pre-dissection stimulation of vagal nerve; R1, pre-dissection stimulation of RLN; V2, post-dissection stimulation of vagal nerve; R2, post-dissection stimulation of RLN. *Definition of normal EMG signal (functionally intact RLN): EMG biphasic waveform, satisfactory amplitude ( $>200 \mathrm{mcV}$ ) and latency. ${ }^{* *}$ If L1 negative, but V1 and R1 EMG signals absent, hypothesize vocal cord injury due to intubation. L2 will demonstrate edema, hematoma, or direct injury to the vocal cord. ^Definition of loss of EMG signal: (a) normal vocal cord movement at L1, (b) initial EMG satisfactory, (c) no EMG response with stimulation at 1-2 mA, (d) low response $<100$ mcV with stimulation at 1-2 mA, (e) no laryngeal twice, (f) neural monitoring trouble shooting algorithm applied systematically.

surgical performance should be evaluated considering the characteristics of the thyroid disease and the data emerging from operative notes. The identification and preservation of nerve should be reported in surgical records, representing a factor for liability admission or rejection. The lack of the data could be justified if the RLN identification is demonstrated as standard of care at institution. However, the identification of nerve may not rule out the admission of surgical error especially in cases showing thyroid disease not complicated. On the other hand, the performed or not identification could be irrelevant in RLN damage considered as nonpreventable complication and, for example, in cases showing severe anatomical alteration due to the gland pathology; in such cases the surgeon liability may be rejected as long as the complication has been disclosed to the patient during the informed consent process. Accordingly, all the information about the thyroid disease belonged from preoperative analysis and, above all, the morphological description of surgical site registered in operative notes are essential for medicolegal evaluation (Table 3). An extensive review of all medical documentation is important and include patient thyroid history, preoperative radiologic imaging, pre-operative symptoms, pre- and postoperative laryngeal examination, exhaustive surgical report with intraoperative findings, identification of RLN, pictures, and videos. All this variables are important to document any pre-existing airway impairment or correct surgical deliberations. Furthermore, we focus on the analysis of possible increased risk factors for RLN injury as the underline thyroid disease (Cancer, Graves' disease increases the risk of nerve injury), patient neck anatomy (increased $\mathrm{BMI})$, the experience of the surgeon, if nerve was identified, if nerve had unpredictable preoperative risk anatomy situation (if described in the surgical report), finally the proper and standardised use of IONM. Subsequently, the discussion of the clinical case must be multidisciplinary with the coroner, a technical expert (surgeon expert in thyroid surgery), the insurer, the hospital administration.

The neuromonitoring can offer data about the intraoperative occurrence of nerve lesion (30-32). Moreover, whilst the usefulness of monitoring in RLN injuries prevention is not unanimously confirmed, the improper use or the non-use could represent a reason for medical malpractice due to error in the surgical technique $(41,48,49)$. However, it is important in the operative notes a statement that demonstrates that the RLN was visualized and was intact (i.e., neural monitoring) at the end of the procedure, especially after the first dominat side/lobe is excised before completion the contralateral side (Table 4).

The RLN damage occurring in the late postthyroidectomy period mostly lead to not detecting liability in surgical activities because it is often related to fibrotic phenomena determining nerve traction or compression.

The above outlined confirms what has been reported by 
other authors regarding to both the surgical information provided to the patient and the details recorded in the clinical documentation (32). The clinical records must be completed accurately and comprehensively to demonstrate that the medical activities have been performed as the practice standard requires. This is because, the data recorded in the documentation have a higher probative value than anamnestic information and testimonial evidence. In case of RLN damage, the correct evaluation of the (a) individual case/disease, (b) the procedure, (c) the position of surgeon (experience), (d) the use of technology (neural monitoring), (e) and comprehensive documentation, are all useful to draw conclusions from the standpoint of surgical deliberations and forensic (41).

Furthermore, the most common approach to treating RLN injuries includes voice therapy and phonomicrosurgery. Treatment begins with voice therapy involving a qualified speech pathologist who works on voice placement and air flow with the patient. Complete abstinence from high modules of vocal sound source for 5-7 days, followed by slow and careful performance at normal phonation, can be very helpful in repairing of normality. A surgeon can employ phonomicrosurgery. From a medico-legal point of view, we believe it is very important (I) the early diagnosis of nerve injury through the routine execution of postoperative laryngoscopy at patient discharge; (II) in the presence of nerve injury, referral of the patient to the voice specialist. There is some evidence in the Literature that the earlier the rehabilitation treatment of the voice, the better the outcomes $(32,48,49)$.

Finally, sources of malpractice litigation in thyroid surgery are not confined to RLN injury (31). According to the review by Abadin et al., all permanent and transient consequences of thyroid surgery costituted malpractice claims (i.e., wound repair, permanent hypocalcemia, wrong site surgery, postoperative bleeding, wrong surgery, unnecessary or inadeguate surgery, delayed surgery, oesophagus perforation, infections and death) (31).

\section{Conclusions}

The evaluation of medical malpractice due to iatrogenic RLN injuries can be difficult. The practitioners involved in the medicolegal analysis of patient complaints related to this thyroidectomy complication need an in-depth knowledge of surgical technique, damage prevention activities and related clinical picture. To this must be added an adequate competence in the evaluation of the causal link (relation between the event and the injury and between that injury and the temporary/permanent impairment) based on the rigorous application of the medicolegal method. In this regards the analisys of causal link need of the forensic practitioners with collaboration of a specialist in this surgery field (1).

\section{Acknowledgments}

Funding: None.

\section{Footnote}

Reporting Checklist: The authors have completed the NARRATIVE reporting checklist. Available at http:// dx.doi.org/10.21037/gs-20-203

Conflicts of Interest: All authors have completed the ICMJE uniform disclosure form (available at http://dx.doi. org/10.21037/gs-20-203). DG serves as an unpaid editorial board member of Gland Surgery from December 2018 to November 2020. The authors have no conflicts of interest to declare.

Ethical Statement: The authors are accountable for all aspects of the work in ensuring that questions related to the accuracy or integrity of any part of the work are appropriately investigated and resolved.

Open Access Statement: This is an Open Access article distributed in accordance with the Creative Commons Attribution-NonCommercial-NoDerivs 4.0 International License (CC BY-NC-ND 4.0), which permits the noncommercial replication and distribution of the article with the strict proviso that no changes or edits are made and the original work is properly cited (including links to both the formal publication through the relevant DOI and the license). See: https://creativecommons.org/licenses/by-nc-nd/4.0/.

\section{References}

1. Gualniera P, Mondello C, Scurria S, et al. Experience of an Italian Hospital Claims Management Committee: A tool for extrajudicial litigations resolution. Leg Med (Tokyo) 2020;42:101657.

2. Norelli GA, De Luca F, Focardi M, et al. The Claims Management Committees Trial: Experience of an Italian Hospital of the National Health System. J Forensic Leg 
Med 2015;29:6-12.

3. Available online: https://www.fnopi.it/wp-content/ uploads/2019/12/Rapporto-PiT-Salute-2019-2.pdf

4. Friedrich T, Hansch U, Eichfeld U, et al. Recurrent laryngeal nerve paralysis ad intubation injury. Chirurg 2000;71:539-44.

5. Efremidou EI, Papageorgiou MS, Liratzopoulos N, et al. The efficacy and safety of total thyroidectomy in the management of benign thyroid disease: a review of 932 cases. Can J Surg 2009;52:39-44.

6. Crinò C, Gualniera P. Il danno ricorrenziale nella chirurgia tiroidea. Aspetti medico-legali. Riv It Med Leg 1994;1:73-93.

7. Makay O, Icoz G, Yilmaz M, et al. The recurrent laryngeal nerve and the inferior thyroid artery-anatomical variations during surgery. Langenbecks Arch Surg 2008;393:681-5.

8. Vuillard P, Bouchet A, Guillat C, et al. Le nerf laryngé inférieur non récurrent. (A propos de quinze cas opératoires) Bull Assoc Anat 1978;62:497-505.

9. Hoon Yub K, Xiaoli L, Hui S, et al. Medico-Legal Issues of Intraoperative Neuromonitoring in Thyroid Surgery. J Endocr Surg 2017;17:42-56.

10. Heinemann M, Kalff G. Possible mechanisms, differential diagnosis and prophylaxis of vocal cord palsy following endotracheal intubation. Anaesthesist 1982;31:353-8.

11. Laursen RJ, Larsen KM, Molgaard J, et al. Unilateral vocal cord paralysis following endotracheal intubation. Acta Anaesthesiol Scand 1998;42:131-2.

12. Hydman J, Björck G, Persson JK, et al. Diagnosis and prognosis of iatrogenic injury of the recurrent laryngeal nerve. Ann Otol Rhinol Laryngol 2009;118:506-11.

13. Riddell V. Thyroidectomy: prevention of bilateral recurrent nerve palsy. Results of identification of the nerve over 23 consecutive years (1946-69) with a description of an additional safety measure. Br J Surg 1970;57:1-11.

14. Have P, Lothian KR. Recurrent laryngeal nerve injury during thyroidectomy. Surg. Gynegol. Obstet 1960;110:448-94.

15. Momoh AO, Ahmed R, Kelley BP et al. A Systematic Review of Complications of Implant-based Breast Reconstruction with Prereconstruction and Postreconstruction Radiotherapy. Ann Surg Oncol 2014;21:118-24.

16. Neumann HJ. Intraoperative neurophysiological monitoring (IONM) of the recurrent laryngeal nerve and microdissection. Surgical techniques for decreasing the risk of recurrent laringeal nerve paralysis. Laryngorhinootologie 2000;79:290-6.
17. Matting H, Bildat D, Metzger B. Reducing the rare of recurrent paralysis by routine exposure of the nerves in thyroid gland operations. Zentralbl Chir 1998;123: 17-20.

18. Joosten U, Brune E, Kersting JU, et al. Risk factors and follow-up of recurrent laryngeal nerve paralysis after first surgeries of benign thyroid diseases. Result of a retrospective analysis of 1.556 patients. Zentralbl Chir. 1997;122: 236-45.

19. Chen W, Liu Y, Wu K, et al. Experience of the laryngeal recurrent nerve dissection in difficult thyroid surgery. Lin Chung Er Bi Yan Hou Tou Jing Wai Ke Za Zhi 2014;28:318-21.

20. Shen C, Xiang M, Wu H, et al. Routine exposure of recurrent laryngeal nerve in thyroid surgery can prevent nerve injury, Neural Regen Res 2013;8:1568-75.

21. Jatzko GR, Lisborg PH, Muller MG, et al. Recurrent nerve palsy after thyroid operations-principal nerve identification and a literature review. Surgery 1994;115:139-44.

22. Chiang FY, Wang LF, Huang YF, et al. Recurrent laryngeal nerve palsy after thyroidectomy with routine identification of the recurrent laryngeal nerve. Surgery 2005;137:342-7.

23. Kasemsuwan L, Nubthuenetr S. Recurrent laryngeal nerve paralysis: a complication of thyroidectomy. J Otolaryngol 1997;26:365-7.

24. Popescu R, Constantinoiu S. Lesions of the laryngeal nerves during thyroidectomy - what's new? Chirurgia (Bucur) 2014;109:439-44.

25. Calò PG, Pisano G, Medas F, et al. Identification alone versus intraoperative neuromonitoring of the recurrent laryngeal nerve during thyroid surgery: experience of 2034 consecutive patients. J Otolaryngol Head Neck Surg 2014;43:16.

26. Kartush JM, Naumann I. Laryngeal nerve monitoring. Neurodiagn J 2014;54:227-59.

27. Fontenot TE, Randolph GW, Setton TE et al. Does intraoperative nerve monitoring reliably aid in staging of total thyroidectomies? Laryngoscope 2015;125:2232-5.

28. Dequanter D, Charara F, Shahla M, et al. Usefulness of neuromonitoring in thyroid surgery. Eur Arch Otorhinolaryngol 2015;272:3039-43.

29. Donatini G, Carnaille B, Dionigi G. Increased detection of non-recurrent inferior laryngeal nerve (NRLN) during thyroid surgery using systematic intraoperative neuromonitoring (IONM). World J Surg 2013;37:91-3.

30. Prokopakis E, Kaprana A, Velegrakis S, et al. Intraoperative recurrent laryngeal nerve monitoring in revision thyroidectomy. Eur Arch Otorhinolaryngol 
2013;270:2521-4.

31. Abadin SS, Kaplan EL, Angelos P. Malpractice litigation after thyroid surgery: the role of recurrent laryngeal nerve injuries, 1989-2009. Surgery 2010;148:718-22.

32. Dralle H, Lorenz K, Machens A. Verdicts on malpractice claims after thyroid surgery: emerging trends and future directions. Head Neck 2012;34:1591-6.

33. Röher HD, Goretzki PE, Hellmann P, et al. Complications in thyroid surgery. Incidence and therapy. Chirurg 1999; 70:999-1010.

34. Tran Ba Huy P, Levy C, Houlbert O, et al. Surgical treatment of Basedow's disease. II--Evaluation of 36 subtotal thyroidectomies. Ann Otolaryngol Chir Cervicofac 1984;101:515-22.

35. Visset J, Lumingo K, Le Bodic MF, et al. La thyriodectomie totale pur prevenie le recidives dans le goitres thyroidiens bènins. Chirurgie 1991;117:37-40.

36. Harris SC. Thyroid and parathyroid surgical complication. Am J Surg 1992;163:476-8.

37. Pironi D, Pontone S, Vendettuoli M, et al. Prevention of complications during reoperative thyroid surgery. Clin Ter 2014; 165:e285-90.

38. Medas F, Tuveri M, Canu G, et al. Complications After Reoperative Thyroid Surgery: Retrospective Evaluation of 152 Consecutive Cases. Updates Surg 2019;71:705-10.

39. Calò PG, Pisano G, Medas F, et al. Risk Factors in Reoperative Thyroid Surgery for Recurrent Goitre: Our Experience. G Chir 2012;33:335-8.

40. Cirocchi R, Trastulli S, Randolph J, et al. Total or NearTotal Thyroidectomy Versus Subtotal Thyroidectomy for Multinodular Non-Toxic Goitre in Adults. Cochrane Database Syst Rev 2015;8:CD010370.

41. Gimm O, Brauckhoff $M$, Thanh PN, et al. An update on thyroid surgery, Eur J Nucl Med Mol Imaging 2002;29:S447-52.

Cite this article as: Gualniera P, Scurria S, Mondello C, Asmundo A, Sapienza D, Dionigi G. Narrative review of proving the causal link of recurrent laryngeal nerve injury and thyroidectomy: a medico legal appraisal. Gland Surg 2020;9(5):1564-1572. doi: 10.21037/gs-20-203
42. Haugen BR, Alexander EK, Bible KC, et al. American Thyroid Association Management Guidelines for Adult Patients With Thyroid Nodules and Differentiated Thyroid Cancer: The American Thyroid Association Guidelines Task Force on Thyroid Nodules and Differentiated Thyroid Cancer. Thyroid 2016;26:1-133.

43. Agarwal G, Aggarwal V. Is total thyroidectomy the surgical procedure of choice for benign multinodular goiter? An evidence-based review. World J Surg 2008;32:1313-24.

44. Ferrara SD, Baccino E, Bajanowski T, et al. EALM Working Group on Medical Malpractice. Malpractice and medical liability. European Guidelines on Methods of Ascertainment and Criteria of Evaluation. Int J Legal Med 2013;127:545-57.

45. Magnussen CR, Patanella HP. Herpes simplex virus and recurrent laryngeal nerve paralysis. Report of a case and review of the literature. Arch Intern Med 1979;139:1423-4.

46. Parano E, Pavone L, Musumeci S, et al. Acute palsy of the recurrent laryngeal nerve complicating Esptein-Barr virus infection. Neuropediatrics 1996;27:164-6.

47. Wackym PA, Gray GF, Avant GR. Herpes zoster of the larynx after intubational trauma. J Laryngol Otol 1986;100:839-41.

48. Schneider R, Randolph GW, Dionigi G, et al. International Neural Monitoring Study Group Guideline 2018 Part I: Staging Bilateral Thyroid Surgery With Monitoring Loss of Signal. Laryngoscope 2018;128:S1-S17.

49. Wu CW, Dionigi G, Barczynski M, et al. International neuromonitoring study group guidelines 2018: Part II: Optimal recurrent laryngeal nerve management for invasive thyroid cancer-incorporation of surgical, laryngeal, and neural electrophysiologic data. Laryngoscope 2018;128:S18-S27. 